Boletim Técnico da Divisão de Experimentação e Pesquisas INSTITUTO A GRONÔMICO

Vol. 12

Campinas, Janeiro-Março de 1952

N. ${ }^{\text {os }} 1-3$

\title{
ESPAÇAMENTO DA BATATA DOCE EM SÃO PAULO
}

\author{
A. Pais de Camargo ( $\left.{ }^{1}\right)$
}

Engenheiro agrônomo, Seç̧ão de Raîzes e Trubérculos, Instituto Agronômico de Campinas

\section{1 - INTRODUÇÃO}

O espargamento utilizado no plantio da batata doce (Ipomcea batatas Lam.), varia bastante no Estado de São Paulo, segundo a região e a finalidade da cultura. Nas plantações intensivas, próximas à capical, visando a produção de batatas para consumo de mesa, são geralmente empregados espaçamentos bastante pequenos, que variam de 50 a $70 \mathrm{~cm}$, entre linhas, e de 15 a $25 \mathrm{~cm}$ entre as plantas, nas linhas. Com espaçamentos assim pequenos, procura-se obter batatas de tamanho relativamente pequeno ou médio, tipo preferido pelos mercados exigentes como os da capital paulista $\left(^{2}\right)$.

No interior do Estado, em plantações mais extensivas, para consumo de mesa ou para fins forrageiros e industriais, adotam-se espaçamentos bem maiores, variando entre 80 a $120 \mathrm{~cm}$ entre linhas, e 40 a $60 \mathrm{~cm}$ entre plantas, nas linhas. Nestes casos, pràticamente, não há exigências quanto ao tipo ou tamanho das raízes. O que interessa, antes de tudo, é o rendimento bruto e a economia de ramas e de trabalho na operação de plantio.

Autores americanos (7) recomendam espaçamentos relativamente grandes, entre linhas e cntre plantas nos casos em que se visa apenas a produção bruta, para forragem ou indústria. Quando, porém, o produto se destina ao mercado, para o consumo de mesa, verificaram ser necessário reduzir o espaçamento entre plantas, a fím de aumentar a produção de raízes de tamanho menor.

Na cultura da batata doce, uma das operações mais trabalhosas e que mais onera a produção é a do plantio. Evidentemente, as despesas, nessa operação, scrão tanto maiores quanto maior fôr o número de plantas, por unidade de superfície, ou seja, quanto menor fôr o espaçamento adotado. Assim sendo, torna-se de interêsse determinar os espaçamentos mais recomendáveis, para cada caso, tendo em vista não só as produções, mas, também, a economia de ramas e de trabalho.

(1) O autor agradcce a colaboração dos engenheiros agrônomos Miguel A. Anderson, Vicente G. de Oliveira, A. Mamprim, Dirceu Pais de Barros, Joâo Alnisi Sobrinho, Lineu C. S. Dias e Mário V. de Morais, chefes de estaçõés experimentais, onde foram realizadas as experiências.

(2) As batatas demasiadamente grandes, com mais de 800 gramas, ou demasiadamente pequenas com menos de 80 gramas são mal aceitas nos mercados e depreciam o produto. 
Com o intuito de estudar o problema, foi iniciado pela Secção de Raízes e Tubérculos dêste Instituto, em 1939/40, um plano experimental, que se estendeu até 1948/49, abrangendo diferentes séries de ensaios. As experiências foram realizadas nas principais regiões agrícolas do Estado e possibilitaram a obtenção de informações aplicáveis à maioria dos casos em que se cultiva essa convolvulácea.

Neste trabalho estão reunidos os resultados de maior interêsse alcançados através do estudo em conjunto, de todos os dados obtidos.

\section{2 - MÉTODO E MATERIAL}

Três séries de ensaios foram efetuadas para estudar o espaçamento para a batata doce, compreendendo um total de dezessete ensaios, distribuídos por cinco diferentes Estações Experimentais do Instituto Agronômico. A primeira série foi composta de duas experiências, instaladas em 1939/40, nas Estações Experimentais de Campinas e Tietê, para estudar, preliminarmente, o efeito de três espaçamentos apenas : um pequeno, de $60 \times 30 \mathrm{~cm}$, um médio, de $75 \times 40 \mathrm{~cm}$ e um grande, de $100 \times 50 \mathrm{~cm}$.

A segunda série compreende duas experiências instaladas no ano seguinte nas mesmas localidades. Visou esta série, tão sòmente, estudar a influência da forma da superfície relativa a cada planta e não o efeito da maior ou menor distância entre elas. Foram adotados três espaçamentos: $100 \times 30 \mathrm{~cm}, 75 \times 40 \mathrm{~cm}$ e $60 \times 50 \mathrm{~cm}$, todos êles com a mesma área por planta $\left(0,30 \mathrm{~m}^{2}\right)$.

A terceira e última série constou de treze ensaios instalados entre 1945/46 e 1948/49, nas Estações Experimentais de Campinas, Tietê, Ribeirão Prêto, Pindorama e Mococa, nos quais foram estudadas, ao mesmo tempo, a influência da área correspondente a cada planta e a influência das distâncias entre linhas e entre plantas. Entraram em competição seis diferentes tratamentos, ou sejam: $60 \times 20 \mathrm{~cm}, 75 \times 20 \mathrm{~cm}, 75 \times 30 \mathrm{~cm}$, $100 \times 30 \mathrm{~cm}, 75 \times 50 \mathrm{~cm} \mathrm{e} 100 \times 50 \mathrm{~cm}$.

Nos ensaios da primeira e segunda séries, não foi feita adubação alguma. Nos da terceira série, mais recentes, foram efetuadas adubações minerais.

Empregaram-se, em todos os ensaios, os métodos de plantio e cultivo usuais no Estado, para a batata doce. Os plantios foram efetuados nos meses de novembro, dezembro e janeiro, e as colheitas, quando as plantas alcançavam o período de repouso, isto é, 5 a 8 meses após o plantio. Em todos os ensaios, nas três séries, utilizaram-se delineamentos em blocos ao acaso, com quatro repetições. Os canteiros tiveram sempre a área útil de $36 \mathrm{~m}^{2}$, com 6 por $6 \mathrm{~m}$. Todos êles foram protegidos por linhas bordaduras para evitar o efeito marginal.

Foram utilizadas nos ensaios as variedades 10-Napoleão, 14-De Arroba, ambas comumente cultivadas no Estado e a 18-Viçosa (1), também conhecida por "Dahomey". Tôdas possuem ramas vigorosas e bastante longas.

(1) Os números das variedades correspondem ao número de introdução no Instituto Agronômico. 
Quadro 1.-Características gerais e respectives tratamentos delineados para os ensaios das três diferentes séries de experiências de espaçamento de batata doce

\begin{tabular}{|c|c|c|c|c|c|}
\hline Ensaios & Variedade & $\begin{array}{l}\text { Adubação } \\
\text { básica (1) }\end{array}$ & $\begin{array}{l}\text { Epoca } \\
\text { de } \\
\text { plantio }\end{array}$ & $\begin{array}{l}\text { Ciclo } \\
\text { vegeta- } \\
\text { tivo }\end{array}$ & Tratamentos \\
\hline \multirow[b]{2}{*}{ FrIMEIRA SERIE dE ENAAIOS } & \multirow[b]{3}{*}{$\begin{array}{l}\text { Napoleão } \\
\text { Napoleão }\end{array}$} & \multirow[b]{3}{*}{$\begin{array}{l}\text { Nenhuma } \\
\text { Nenhuma }\end{array}$} & \multirow[t]{2}{*}{ Data } & \multirow[t]{2}{*}{ Meses } & \multirow[b]{3}{*}{$\begin{array}{c}\text { 60x30, } \\
\text { Idem }\end{array}$} \\
\hline & & & & & \\
\hline $\begin{array}{l}\text { 1.0 Campinas }-1939 / 40 \ldots \\
\text { 2.0 Tieté }-1939 / 40 \ldots\end{array}$ & & & $\begin{array}{l}30 \text { Nov. } \\
22 \text { Jan. }\end{array}$ & $\begin{array}{l}7 \\
6\end{array}$ & \\
\hline SEgUNDA sERIE DE ENBaIOS & \multirow[b]{2}{*}{$\begin{array}{l}\text { Napoleăo } \\
\text { Napoleăo }\end{array}$} & \multirow[b]{2}{*}{$\begin{array}{l}\text { Nenhuma } \\
\text { Nenhuma }\end{array}$} & \multirow[b]{2}{*}{$\begin{array}{l}26 \text { Dez. } \\
20 \text { Dez. }\end{array}$} & & \multirow[b]{2}{*}{ 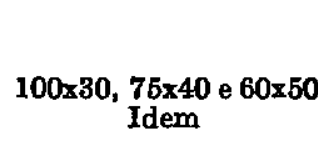 } \\
\hline $\begin{array}{l}\text { 3.0 Tiete }-1940 / 41 \\
\text { 4.0 Campinas }-1940 / 41 .\end{array}$ & & & & $\begin{array}{l}6 \\
6\end{array}$ & \\
\hline TERCEIra SERIE DE ENSAIOS & \multirow[b]{2}{*}{ Viçosa } & \multirow[b]{2}{*}{ Nenhuma } & \multirow[b]{2}{*}{7 Dez. } & \multirow[b]{2}{*}{8} & \multirow[b]{2}{*}{$\begin{array}{l}60 \times 20,75 \times 20,75 \times 30 \\
100 \times 30,75 \times 50 e^{-} \\
\left.100 \times 50{ }^{2}\right)\end{array}$} \\
\hline 6.0 Campinas - 1945/46 & & & & & \\
\hline $\begin{array}{l}\text { 8.0 Tieté }-1945 / 46 \\
\text { 10.0 Tietê }-1946 / 47 \\
14.0 \text { Tietê }-1947 / 48 \\
\text { 18.0 Tietế }-1948 / 49\end{array}$ & $\begin{array}{l}\text { Viçosa } \\
\text { Vicosa } \\
\text { Viçosa } \\
\text { Viçosa }\end{array}$ & $\begin{array}{l}\text { Nenhuma } \\
60-100-40 \\
60-100-40 \\
60-100-40\end{array}$ & $\begin{array}{l}12 \text { Dez. } \\
27 \text { Nov. } \\
19 \text { Jan. } \\
14 \text { Dez. }\end{array}$ & $\begin{array}{l}\mathbf{8} \\
\mathbf{8} \\
\mathbf{5} \\
\mathbf{8}\end{array}$ & $\begin{array}{l}\text { Idem } \\
\text { Idem } \\
\text { Idem } \\
\text { Idem }\end{array}$ \\
\hline $\begin{array}{l}\text { 9.0 Rib. Prêto }-1945 / 46 \\
\text { 12.0 Rib. Prêto }-1946 / 47=- \\
\text { 16.0 Rib. Préto }-1947 / 48\end{array}$ & $\begin{array}{l}\text { De Arroba } \\
\text { De Arroba } \\
\text { De Arroba }\end{array}$ & $\begin{array}{l}\text { Nenhuma } \\
60-100-40 \\
60-100-40\end{array}$ & $\begin{aligned} 23 & \text { Nov. } \\
5 & \text { Nov. } \\
15 & \text { Nov. }\end{aligned}$ & $\begin{array}{l}7 \\
7 \\
8\end{array}$ & $\begin{array}{l}\text { Idem } \\
\text { Idem } \\
\text { Idem }\end{array}$ \\
\hline $\begin{array}{l}\text { 11.0 Pindorama }-1946 / 47 \ldots \\
17 . .\end{array}$ & $\begin{array}{l}\text { Viçosa } \\
\text { Viçosa }\end{array}$ & $\begin{array}{l}60-100-40 \\
60-100-40\end{array}$ & $\begin{array}{l}11 \text { Dez. } \\
13 \text { Jan. }\end{array}$ & 8 & $\begin{array}{l}\text { Idem } \\
\text { Idem }\end{array}$ \\
\hline $\begin{array}{l}\text { 13.0 Mococa }-1946 / 47 \\
15 . .^{\circ} \text { Mococa }=1947 / 48 \\
19 . .^{\circ} \text { Mococa }-1948 / 49\end{array}$ & $\begin{array}{l}\text { Viçosa } \\
\text { Viçosa } \\
\text { Viçosa }\end{array}$ & $\begin{array}{l}60-100-40 \\
60-100-40 \\
60-100-40\end{array}$ & $\begin{array}{l}24 \text { Dez. } \\
11 \text { Dez. } \\
11 \text { Jan. }\end{array}$ & $\begin{array}{l}7 \\
7 \\
8\end{array}$ & $\begin{array}{l}\text { Idem } \\
\text { Idem } \\
\text { Idem }\end{array}$ \\
\hline
\end{tabular}

(1) $\mathrm{O}_{8}$ números indicam, respectivamente, a aplicação, em quilogramas por hectare, de $\mathrm{N}, \mathrm{P}_{2} \mathrm{O}_{5}$ e $\mathrm{K}_{2} \mathrm{O}$.

(2) Nos ensaios instalados no ano agrícola de 1945/46, os dois altimos tratamentos tiveram $40 \mathrm{~cm}$ de distancia entre plantas, nas linhas.

No quadro 1 estão indicadas as características do plano e os delineamentos adotados nesses ensaios.

\section{3 - RESULTADOS EXPERIMENTAIS}

Para estudar o comportamento da batata doce plantada com os diferentes espaçamentos foram feitas várias observações, a saber: a) desenvolvimento de ramas; $b$ ) ocorrência de falhas ; $c$ ) classificação, pesagens e contagens do produto.

Nos quatro primeiros ensaios, pertencentes à primeira e à segunda séries, as bases adotadas na classificação foram as seguintes:

classe miúda - raízes com pêso inferior a 150 gramas;

classe média - raízes pesando entre 150 a 1000 gramas;

classe graúda - raízes com mais de 1100 gramas. 
Nos ensaios ulteriores, da terceira série, êsse critério, visando torná-lo mais de acôrdo com as exigências do mercado, foi alterado para o seguinte :

classe miúda - raízes com menos de 80 gramas, excluído o refugo ( ${ }^{2}$; classe média - raízes com pêso entre 80 a 800 gramas e sem defeitos de conformação;

classe defeituosa - raízes com pêso entre 80 e 800 gramas apresentando defeitos que as tornam impróprias para o mercado;

classe graúda - raízes com mais de 800 gramas.

Como não se observou qualquer efeito dos espaçamentos sôbre a ocorrência das raízes defeituosas, estas foram consideradas englobadamente com as raízes da classe média.

Foram incluidos neste trabalho ùnicamente os dados relativos ao desenvolvimento das ramas, à produção bruta de raízes, aos pesos médios das raízes, e, nos ensaios da terceira série, os dados referentes às percentagens de falhas e às produções dos diferentes tipos de raízes. Todos êsses dados

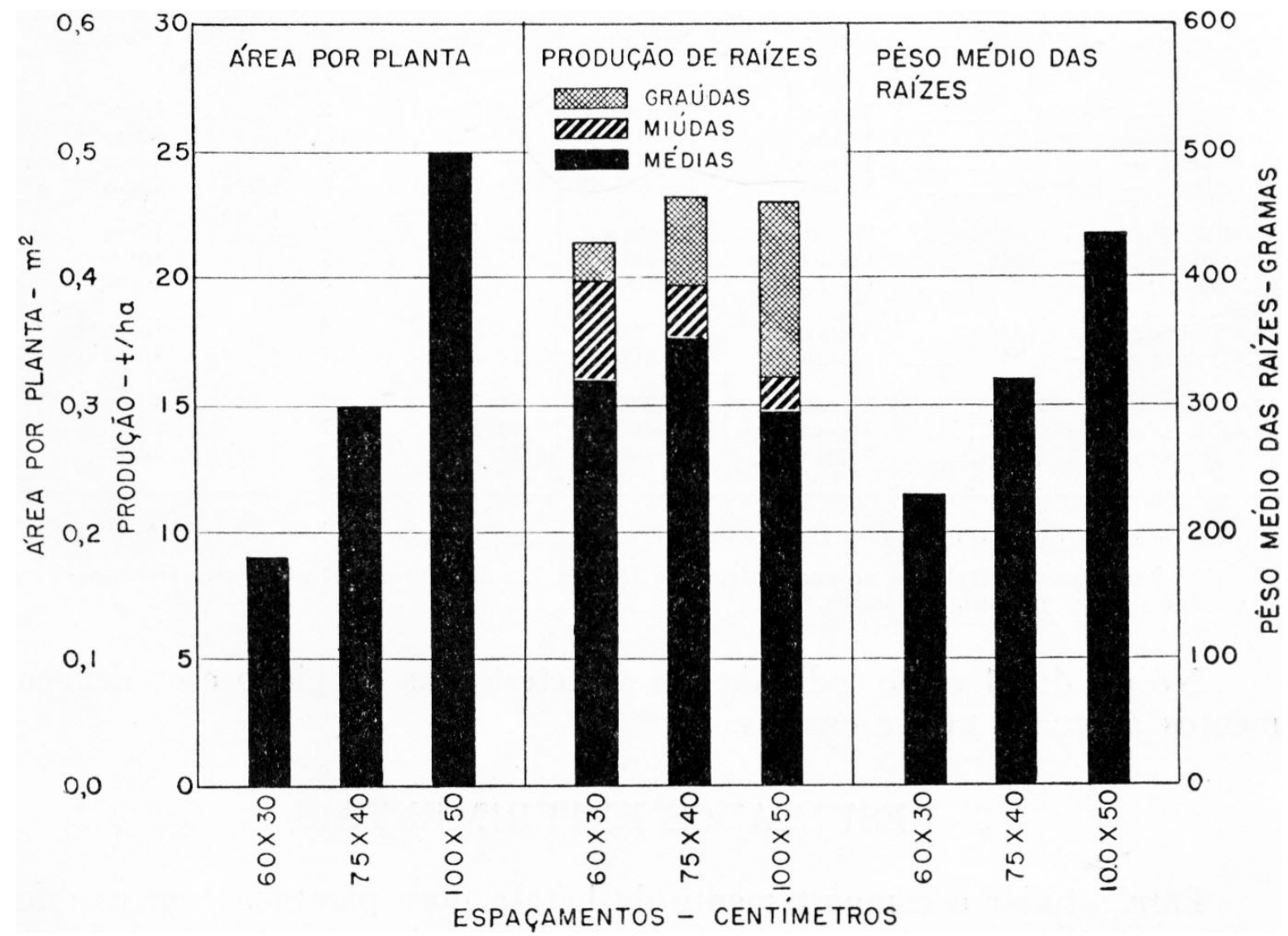

Ficura 1. - Representação gráfica das áreas correspondentes a cada planta, das produções médias de raízes de tamanho médio, miúdo e graúdo, e dos pesos médios das rázes dos três diferentes espaçamentos estudados nos ensaios da primeira série experimental.

aparecem reunidos em quadros e se referem às médias, por tratamento, obtidas em cada ensaio, ou em grupo de ensaios, reunidos por localidade.

(1) Refugo corresponde a r afzes improprias para o mercado, muito pequenas ou afiladas, no geral, com peso inferior a 30 gramas. 
São também apresentadas, nos quadros, as diferenças mínimas significativas para o limite de $P=0,05$ e os coeficientes de variação (').

\section{1 - PRIMEIRA SÉRIE DE ENSAIOS}

Nesta série constam dois ensaios instalados com a variedade 10Napoleão (2), nas Estações Experimentais de Campinas e Tietê, cm 1939/40. Foram estudados os efeitos de três espaçamentos: pequeno - $60 \times 30 \mathrm{~cm}$; médio - $75 \times 40 \mathrm{~cm}$ e grande $100 \times 50 \mathrm{~cm}$, sôbre o desenvolvimento das ramas, produção bruta, de raízes das classes miuda, média e graúda, e pêso médio das raízes. Os dados referentes às produções e pesos figuram no quadro 2, e estão representados gràficamente na figura 1.

Desenvolvimento das ramas - Ambos os ensaios vegetaram muito bem. Pràticamente, não se observaram diferenças senșiveis no desenvolvimento das ramas, que possam ser atribuídas aos diferentes tratamentos.

Quadro 2.-Produções médias de raízes de batata doce, por unidade de superfície, dos vários tipos, pesos médios das raizes e producões médias por planta, obtidas por tratamento nos dois ensaios da primeira série - Média de quatro repetições

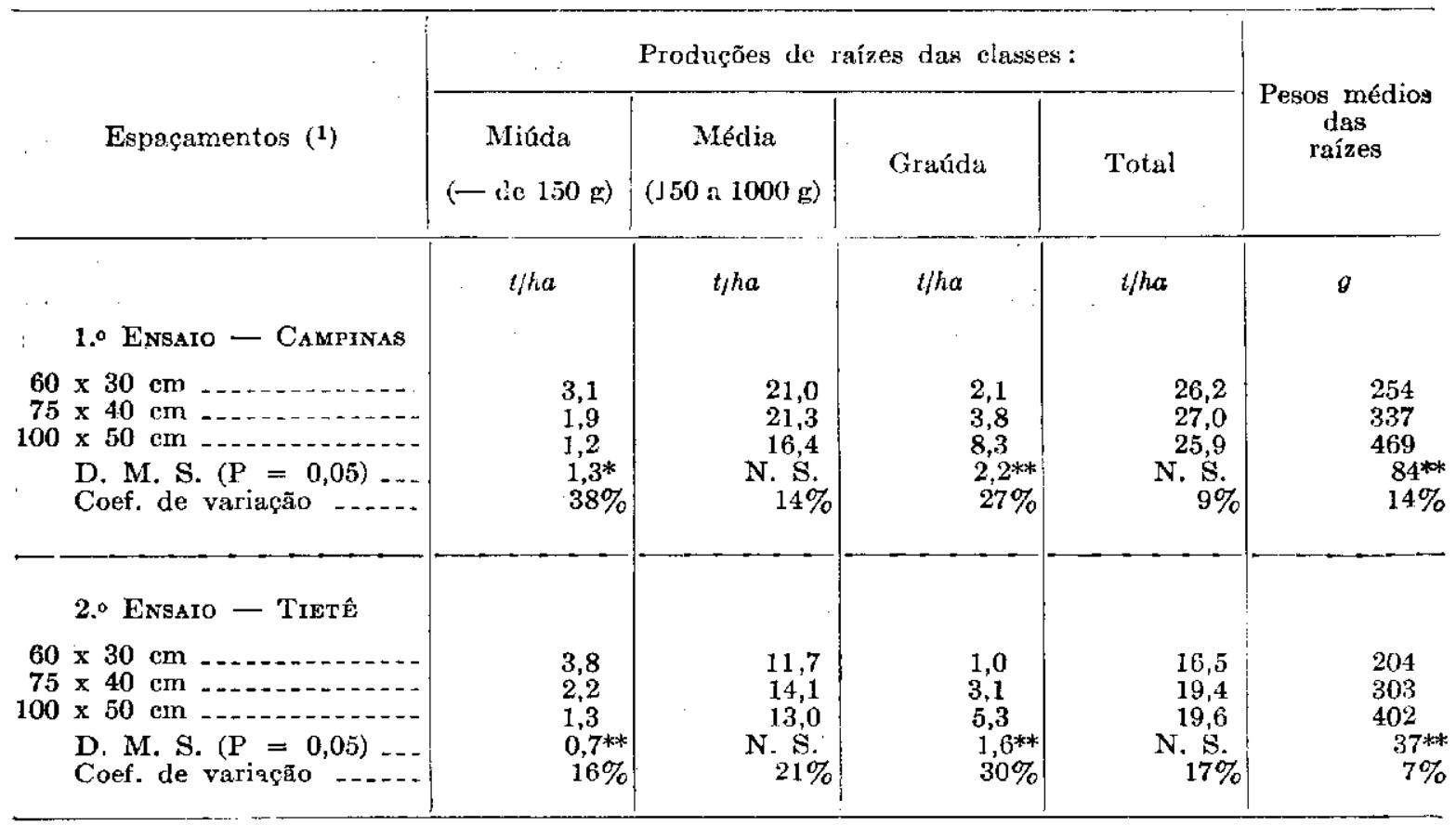

* " $F$ " significativo; ** " $F$ " altamente signuficativo $=0.50 \mathrm{~m}^{2}$.

(1) Áreas correspondentes por planta: $60 \times 30 \mathrm{~cm}=0,18 \mathrm{~m}^{2} ; 75 \times 40 \mathrm{~cm}=0,30 \mathrm{~m}^{2} ; 100 \times 50 \mathrm{~cm}$

Produção - As produções obtidas em ambos os ensaios, desta série, foram bastante satisfatórias e relativamente elevadas, sobretudo as do $2 .^{\circ}$ ensaio, de Campinas (quadro 2). Com os resultados obtidos, podem scr feitas as seguintes observações:

a) Os espaçamentos entre linhas e cntre plantas nos limites estudados, não tiveram influência significativa sôbre a produção bruta de raízes por

(1) Coeficiente de variação $=\mathrm{s} \frac{100}{\overrightarrow{\mathrm{x}}}$

(2) Esta variedade tossui as fôlhas inteiras cordiformes, com as nervuras roxas na base e proximidades, na página inferinr; quando novas, a lâmina das fôlhas upresenta-se, muitas vêzes, arroxeada. As raizes são alongadas, geralmente fusiformes e coloridas de ereme, externa e internamente. 
unidade de área, seja com relação à produção de raízes de tamanho médio (150 a $1000 \mathrm{~g}$ ), ou à produção total bruta.

b) Os espaçamentos mostraram considerável influência sôbre as produções das raízes miúdas (menos de $150 \mathrm{~g}$ ), bem como de graúdas (mais de $1000 \mathrm{~g}$ ). Com relação à classe miúda, obtiveram-se, no espaçamento de $60 \times 30 \mathrm{~cm}$, produções significativamente bem mais elevadas que nos demais. $O$ contrário ocorreu em relação às raízes graúdas, das quais produções bem maiores foram obtidas com o emprêgo do maior espaçamento, isto é, de $100 \times 50 \mathrm{~cm}$.

Pêso médio das raízes $-O$ pêso médio (produção total dividida pelo número de raízes produzidas, excluídas as de refugo) mostrou-se bastante influenciado pelo espaçamento. Como se pode observar pelos dados da última coluna do quadro 2 , houve nítida correlação, em ambos os ensaios, entre o espaçamento e os respectivos pesos médios de raízes. À mədida que se aumentou o espaçamento, aumentou tamb'm o tamanho das batatas collinas.

\section{2 - SEGUNDA SÉRIE DE ENSAIOS}

Esta sórie compõe-se de dois ensaios instalados em 1940/41, nas mesmas estações experimentais onde foram plantados os ensaios da primeira série. O ensaio de Tietê recebeu o núməro 3 e o de Campinas, o número 4 ; ambos foram plantados com a variedade 10-Napoleão.

Nos ensaios foram estudados três espaçamentos distintos, variando as distâncias entre plantas e entre linhas, mas mantendo em todos êles a mesma área de $0,30 \mathrm{~m}^{2}$, por planta. Os tratamentos foram : $100 \times 30 \mathrm{~cm}, 75 \times 40 \mathrm{~cm}$ e $60 \times 50 \mathrm{~cm}$.

Quadro 3.--Produções de raízes, em toneladas por hectare, das classas miúda, média e graúda e pesos médios das raízes, em gramas, obtidos para cada tratamento estudado na segunda série de ensaios. Médias de 4 repetições

\begin{tabular}{|c|c|c|c|c|c|}
\hline \multirow[b]{2}{*}{ Espaçamentos $\left(0,30 \mathrm{~m}^{2}\right)$} & \multicolumn{4}{|c|}{ Produçōes de raízes das classes } & \multirow{2}{*}{$\begin{array}{l}\text { Pesos médios } \\
\text { das } \\
\text { raízes }\end{array}$} \\
\hline & $\begin{array}{c}\text { Miúda } \\
(- \text { de } 150 \mathrm{~g})\end{array}$ & $\begin{array}{c}\text { Média } \\
(150 \text { a } 1000 \mathrm{~g})\end{array}$ & $\begin{array}{c}\text { Graúda } \\
(+ \text { de } 1000 \mathrm{~g})\end{array}$ & Total & \\
\hline & $t / h a$ & t/ha & t/ha & t/ha & $g$ \\
\hline 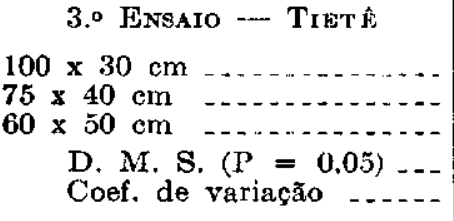 & $\begin{array}{r}3,5 \\
4,2 \\
3,7 \\
\mathrm{~N} . \mathrm{g} \\
12 \%\end{array}$ & $\begin{array}{r}11,6 \\
10,8 \\
10,7 \\
N . S . \\
13 \%\end{array}$ & $\begin{array}{r}6,9 \\
3,5 \\
3,3 \\
\mathrm{~N} . \mathrm{S} \\
44 \%\end{array}$ & $\begin{array}{c}22,0 \\
18,5 \\
\mathrm{j} 7,7 \\
2,1 \\
\mathbf{6 \%}\end{array}$ & $\begin{array}{c}232 \\
204 \\
204 \\
\text { N. S. } \\
12 \%\end{array}$ \\
\hline $\begin{array}{l}4.0^{\circ} \text { Engato - CaupiNas } \\
100 \times 30 \mathrm{~cm} \\
75 \times 40 \mathrm{~cm} \\
60 \times 50 \mathrm{~cm}-\ldots \\
\text { D. M. S. (l' }=0,05) \\
\text { Coef. de variação }\end{array}$ & $\begin{array}{l}6,8 \\
5,2 \\
4,5 \\
1,8 * \\
19 \%\end{array}$ & $\begin{array}{r}9,8 \\
9,6 \\
9,1 \\
\text { N. S. } \\
17 \%\end{array}$ & $\begin{array}{r}1,8 \\
1,3 \\
2,1 \\
\mathrm{~N} . \mathrm{S} \\
34 \%\end{array}$ & $\begin{array}{c}18,4 \\
16,1 \\
15,7 \\
\mathrm{~N} . \mathrm{S} . \\
9 \%\end{array}$ & $\begin{array}{c}169 \\
158 \\
170 \\
\text { N. S. } \\
4 \%\end{array}$ \\
\hline
\end{tabular}


Desenvolvimento das ramas - Ambos os ensaios vegetaram bem. Não foram encontradas diferenças sensíveis no desenvolvimento das ramas, devidas aos tratamentos. Observam-se, entretanto, canteiros com reboleiras de plantas mais fracas, o que se pode atribuir à desuniformidade do solo.

Produção - Pelo exame do quadro 3, onde figuram os dados sôbre a produção, podem ser feitas as seguintes observações:

a) No ensaio de Tietê (n. ${ }^{\circ}$ ), verificou-se efeito significativo dos tratamentos sôbre a produção bruta de raízes, sendo a produção do tratamento $100 \times 30 \mathrm{~cm}$ superior às dos demais. No outro ensaio de Campinas ( ${ }^{\circ}$ 4), embora a análise estatística não tenha revelado diferenças significativas, observaram-se produções médias mais elevadas nesse espaçamento. Êsses resultados indicaram que houve, com relação à produção, vantagem dos tratamentos com maiores distâncias entre linhas e menores entre as plantas, nas linhas.

b) Com relação às produções das classes miúda, média e graúda, não se observaram quaisquer efeitos dos diferentes espaçamentos experimentados.

Pêso médio das raízes - Não se observaram, também, efeitos significantes dos três espaçamentos adotados nesta série de ensaios, sôbre o pêso médio das raízes colhidas (quadro 3).

\section{3 - TERCEIRA SÉRIE DE ENSAIOS}

Seis combinações de espaçamentos entre linhas e plantas nas linhas, foram estudadas na terceira série de ensaios. Planejaram-se os espaçamentos de modo a proporcionar áreas crescentes às plantas. Foram os seguintes os espaçamentos e respectivas áreas por planta:

Tratamentos

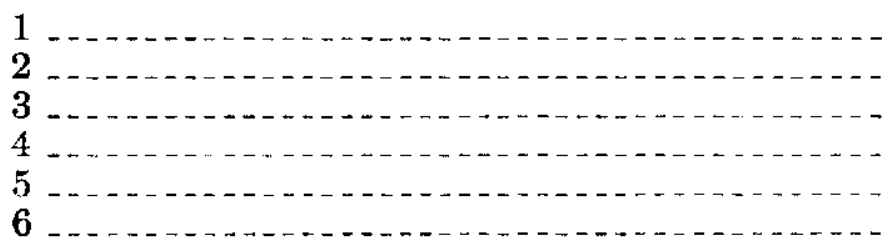

Espaçamento $\mathrm{cm}$

$60 \times 20$

$75 \times 20$

$75 \times 30$

$100 \times 30$

$75 \times 50$

$100 \times 50$
Area por planta

$m^{2}$

0,12

0,15

0,22

0,30

0,37

0,50

Ao todo, foram plantados treze ensaios em cinco estações experimentais : um em Campinas, quatro em Tietê, três em Ribeirão Prêto, dois em Pindorama e três em Mococa. Em todos os ensaios, com exceção dos instalados em Ribeirão Prêto, utilizou-se a variedade 18-Viçosa (Dahomey) (1). Nessa estação experimental, foi plantada a variedade 14-De Arroba (2), comumente cultivada na regiãc.

Com exceção de três ensaios plantados em 1945/46, que não foram adubados, todos os outros receberam, na ocasião do plantio, uma mistura com-

(1) Variedade de fôlhas inteiras, ramas verde-arroxeadas possuindo raízes com periderme e c6rtex roxo e a polpa creme.

(2) Variedade de fôlhas fendidas e folhagem verde-bronzeada; as raízes são mais ou menos cilíndricas e de côr creme, externa e internamente. É também conhecida pelo nome de Raínha. 
pleta de adubos solúveis, na base de $60 \mathrm{~kg}$ de nitrogênio, $100 \mathrm{~kg}$ de ácido fosfórico e $40 \mathrm{~kg}$ de óxido de potássio, por hectare. As adubações minèrais aplicadas no ano, têm geralmente pouca influência sôbre a produção de batata doce, quando aplicadas em terras de fertilidade não muito baixa (9). Por êste motivo, pôde-se estudar em conjunto os resultados de todos os ensaios da série, embora os três primeiros não tenham sido adubados.

Desenvolvimento das ramas - De modo geral, os ensaios desta série apresentaram bom desenvolvimento das ramas. Apenas nos ensaios realizados na Estação Experimental de Ribeirão Prêto, em solo de baixa fertilidade, as ramas mostraram um desenvolvimento inferior (quadro 4).

QUADRo 4.-Desepvolvimento geral das ramas, por ensaio e percentagens médias de falhas, por tratamento, observadas por ocasião da colheita, nas experiências da terceira série de ensaios de espaçamento de batata doce

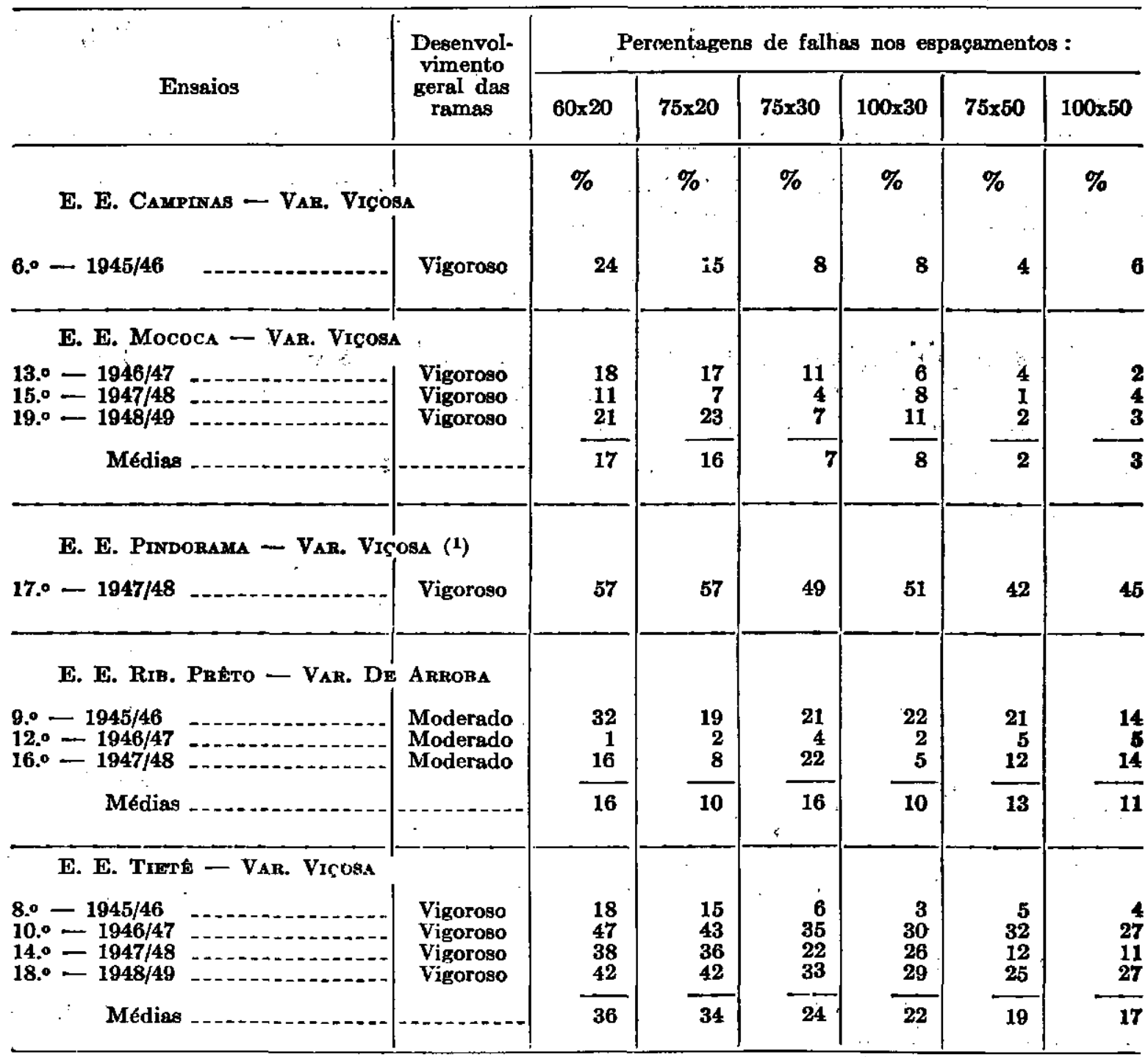

(1) No 11.0 Ensaio de Pindorama, não foram feitas contagens de falhas. 


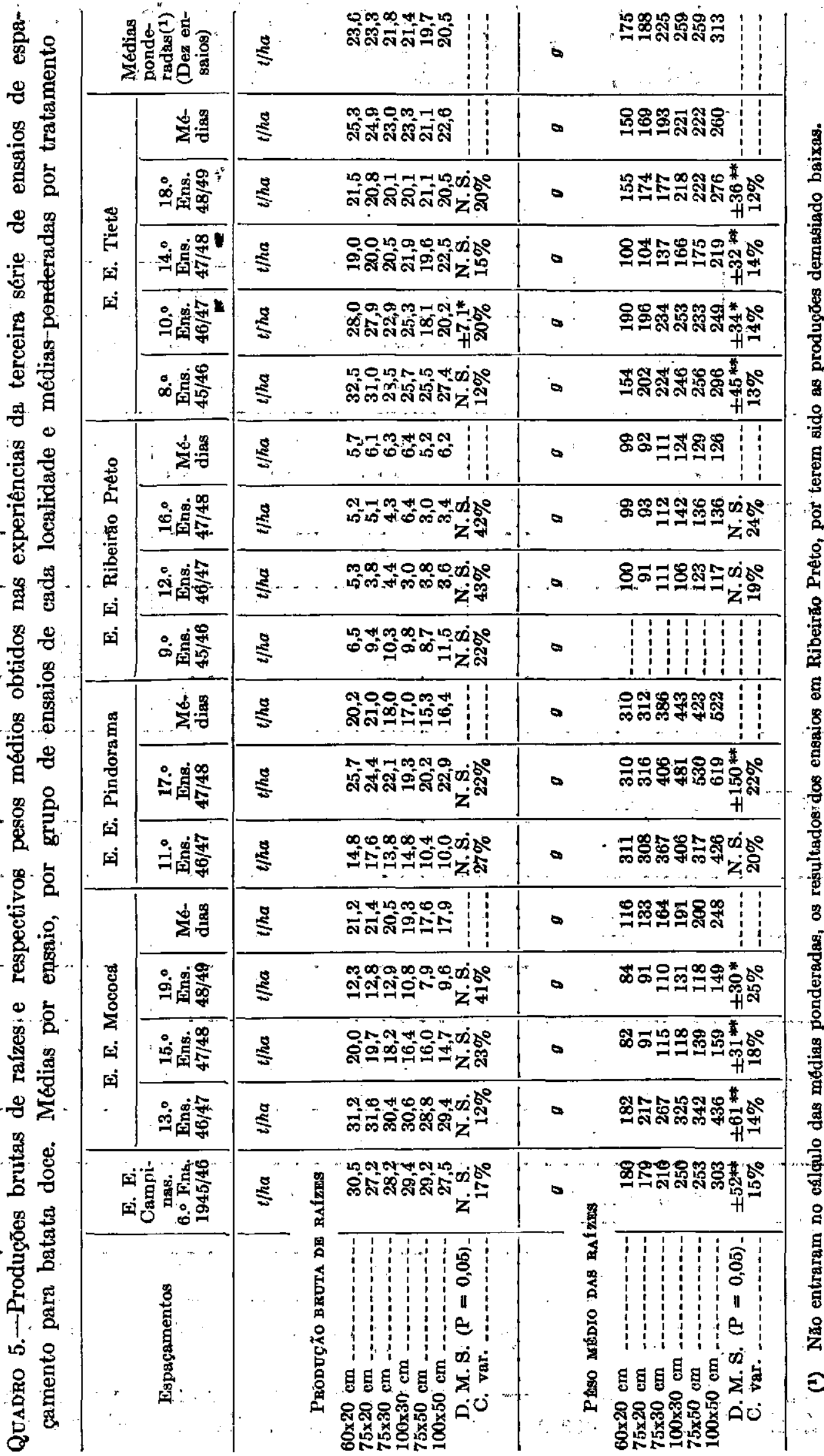


Os diferentes espaçamentos experimentados, de modo geral, não influenciaram o desenvolvimento das ramas. Nos canteiros com espaçamento grande, de $100 \times 5 i) \mathrm{cm}$, as ramas se desenvolveram de modo a cobrir totalmente o solo.

Quadro 6.-Produções de raízes de batata doce, em quilogramas por hectare, das classes : miúda (de 30 a 80 gramas), média (de 80 a 800 gramas), graúda (mais de 800 gramas), obtidas em média para cada uma das cinco estações experimentais, onde foram instalados os ensaios da terceira série

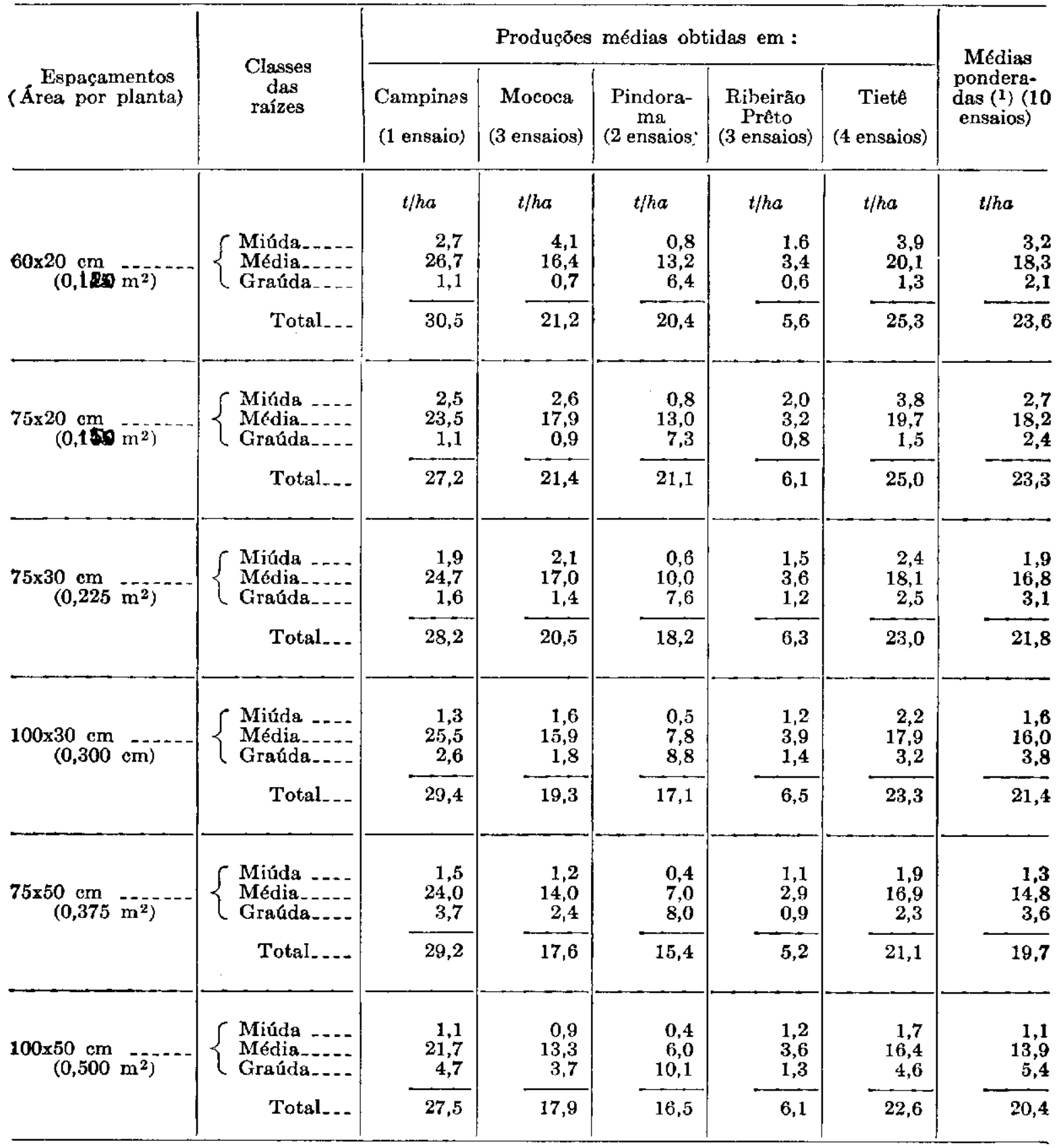

(1) Năo entraram no cálculo das médias ponderadas, os dados dos ensaios plantados em Ribeirão Prêto, por terem sido anormalmente baixas as produçōes.

Ocorrência de falhas - $O$ espaçamento mostrou, por sua vez, ter apreciável influência sôbre a ocorrência de falhas. Examinando-se, no qua- 
dro 4, os dados referentes aos ensaios de Campinas, Mococa e Tietê, verifica-se que as percentagens de falbas decresceram gradativamente à medida que aumentou o espaçamento. De fato, nos ensaios dessas localidades, para o maior e o menor espaçamento, isto $6,100 \times 50 \mathrm{~cm}$ e $60 \times 30 \mathrm{~cm}$, obtiveramse, respectivamente, as seguintes percentagens de falhas: em Campinas - $24 \%$ e $6 \%$, em Mococa - $17 \%$ e $3 \%$ e em Tietê - $36 \%$ e $17 \%$.

Nos ensaios de Pindorama e Ribeirão Prêto não se observaram efeitos consistentes dos espaçamentos sôbre as percentagens de falhas. Em Pindorama, essa diferença de comportamento poderá ser atribuída às elevadas percentagens de falhas que ocorreram em todo o ensaio (n. $\left.{ }^{\circ} 17\right)$. Em Ribeirão Prêto, por sua vez, as plantas, com um desenvolvimento geral muito fraco, não chegaram a crescer o suficiente para prejudicar ou dominar as plantas vizinhas.

Produção bruta - Com exceção dos três ensaios plantados na Estação Experimental de Ribeirão Prêto, onde as produções foram excessivamente baixas, inferiores a 10 toneladas por hectare, obtiveram-se nesta série experimental resultados satisfatórios, que permitiram reunir informações suficientemente seguras. Em oito dos ensaios, os coeficientes de variação mostraram-se inferiores a $25 \%$ (quadro 5).

Analisando-se isoladamente os ensaios, verifica-se que, via de regra, as produçбes brutas não se mostraram significativamente influenciadas pelos єspaçamentos. Apenas em um dos ensaios da terceira série, o $10 .^{\circ}$ de Tietê, o teste de "F" (Snedecor), para tratamentos, se mostrou significativo para $\mathbf{P}=0,05$. Tomando, porém, em conjunto, os dados de dez dos ensaios, cujas produçôes médias podem ser consideradas, normais, isto é, superiores a 10 t/ha, observa-se sensível efeito das distâncias entre plantas sôbre as produçz̃es brutas, as quais aumentaram sensivelmente à medida que diminuiu o espaçamento. As distâncias entre linhas, todavia, nos limites estudados, não mostraram afetar, de modo consistente, as produções brutas de raízes por unidade de superfície (figura 2). Reunindo-se também os dados, por estação experimental, obtêm-se resultados semelhantes. Apenas em Campinas, onde se plantou um único ensaio, e em Ribeirão Prêto, onde as produções foram anormais, não se verificaram influências dos espaçamentos.

Classificação das raízes - Observaram-se, nos ensaios desta série, efeitos bastante sensíveis do espaçamento sôbre a produção de raízes das três classes: miúda, média e graúda. Analisando-se os dados do quadro 6, pode-se verificar que a produção das raízes miúdas e médias diminuiu bastante à medida que aumentou o espaçamento.

Comparando-se os resultados dos dois espaçamentos extremos : $60 \times 20$ e $100 \times 50 \mathrm{~cm}$, pode-se verificar que as produções variaram de 3,2 para $1,1 \mathrm{t} / \mathrm{ha}$, no caso das batatas miúdas e de 18,3 para $13,9 \mathrm{t} / \mathrm{ha}$, no caso de tamanho médio. Por outro lado, as produções de batatas graúdas aumentaram sensìvelmente com o acréscimo de espaçamento, passando de 2,1 t/ha, no espaçamento de $60 \times 20 \mathrm{~cm}$, para $5,4 \mathrm{t} / \mathrm{ha}$ no espaçamento de $100 \mathrm{x}$ $50 \mathrm{~cm}$. Observou-se também que, em Pindorama, em relação às outras localidades, obtiveram-se produções bem mais elevadas de batatas de classe 


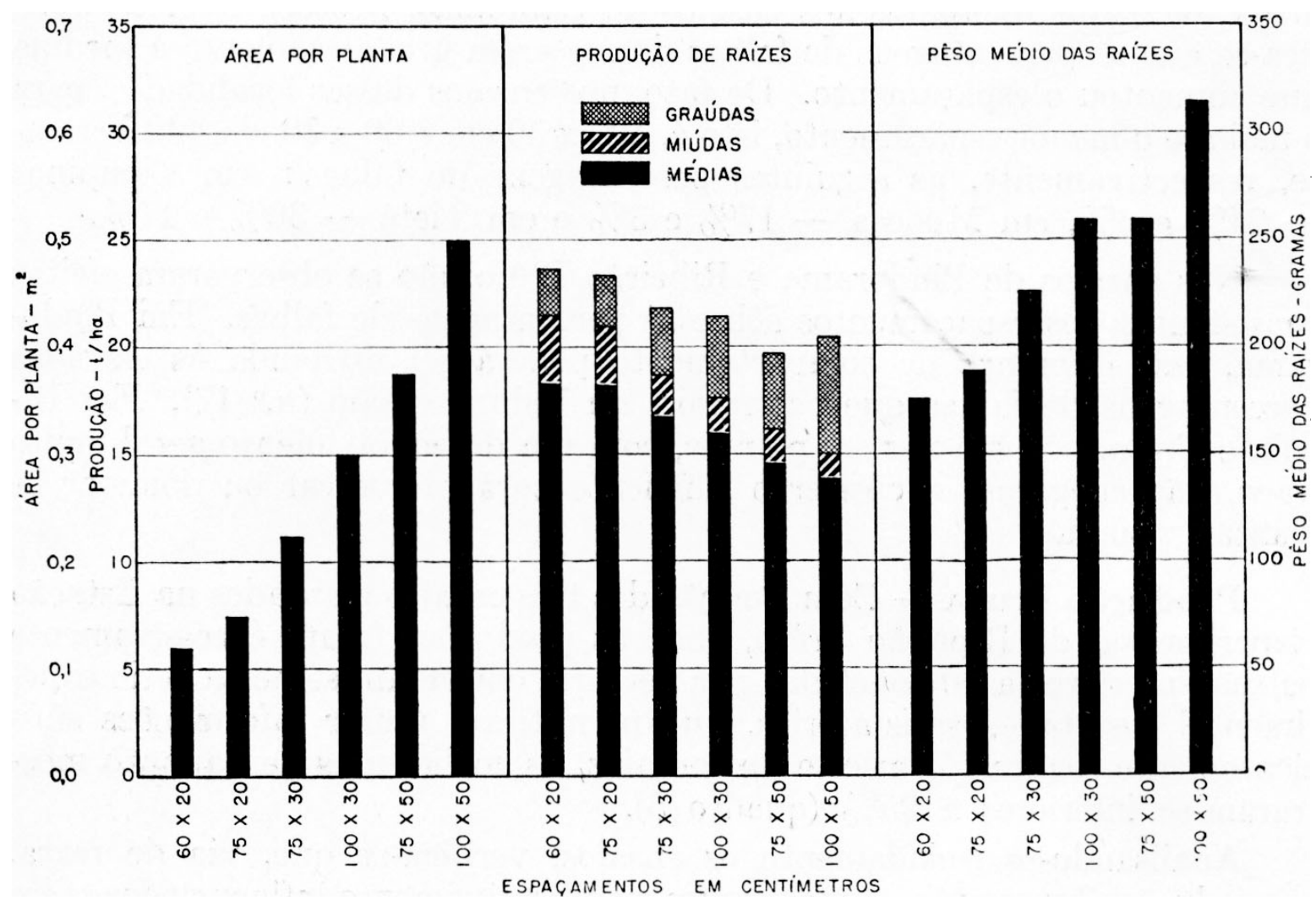

Ficura 2. - Representação gráfica das áreas correspondentes a cada planta, das produções médias de raízes de tamanho médio, miúdo e graúdo, e dos pesos médios das raízes para os seis tratamentos estudados nos dez ensaios da terceira série experimental, que apresentaram produções normais.

graúda. Isto, provàvelmente, se deve ao fato de essa estação experimental estar localizada em solo do "arenito de Bauru", que é bastante leve, propiciando o desenvolvimento das raízes.

Pêso médio das batatas - Os dados que figüram no quadro 7 mostram que o pêso médio das raízes, ou melhor, o seu tamanho médio foi bastante influenciado pelo espaçamento. Mesmo considerando os ensaios, individualmente, observa-se estreita correlação entre o espaçamento e os pesos médios das raízes.

Em sete, dentre os doze ensaios, nos quais se fizeram contagens de batatas, obteve-se, pelo teste de " $F$ " (Snedecor), alta significância para tratamentos. Em outros dois ensaios observou-se, ainda, significância para $\mathbf{P}=0,05$.: Apenas nos dois ensaios de Ribeirão Prêto; cnde as produções se mostraram anormalmente baixas, não se verificou, pelo teste " $F$ ", significância para tratamentos.

Os pesos médios das batatas variaram bastante de uma para outra localidade. Em Pindorama, onde o ensaio foi plantado em local de terra "arenito Bauru", obtiveram-se, de modo geral, os maiores pesos médios de raízes. Em Campinas, Mococa e Tietê, nos ensaios localizados em solos mais argilosos, os pesos médios foram bem mais baixos. 
Forma das raízes - Observações diversas efetuadas nos ensaios não permitiram observar efeitos apreciáveis dos espaçamentos sôbre a forma das batatas colhidas.

\section{4 - DISCUSSÃO}

Os"resultados isolados de cada ensaio, raramente mostraram efeitos significativos dos espaçamentos usados sôbre as produções brutas. Reunindo-se, porém, os resultados dos vários ensaios, da terceira série, pôde-se observar uma tendência para o aumento da produção à medida que se diminuiram os espaçamentos entre as plantas nas linhas. Com a menor distância experimentada, de $20 \mathrm{~cm}$, obteve-se a produção máxima (figura 3). Por sua vez, as distâncias usadas, entre linhas oú seja entre camalhóes, não revelaram qualquer efeito consistente sôbre as respectivas produções brutas.

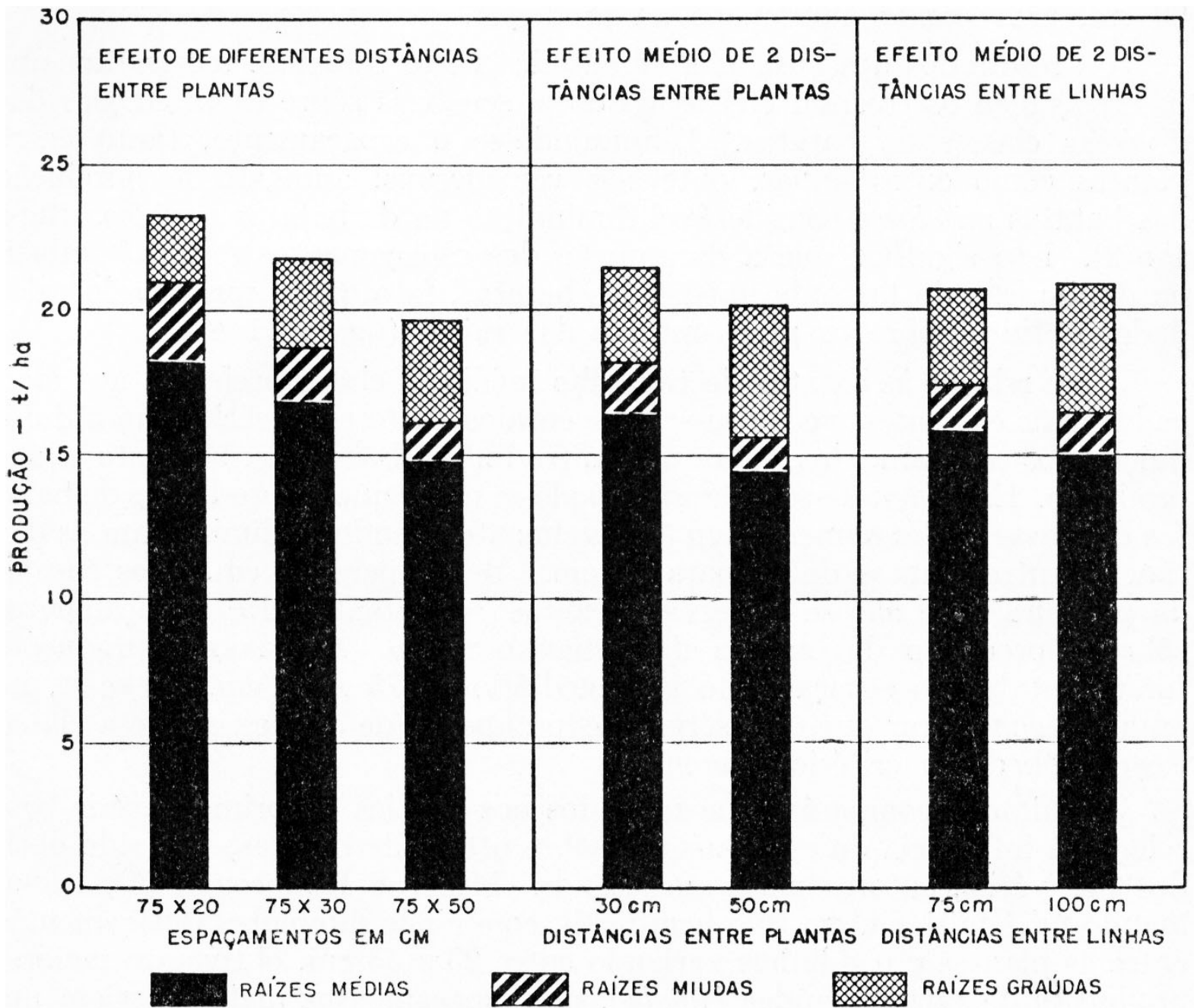

Figura 3. - Efeito das distâncias entre plantas e das distâncias entre linhas sôbre as produções de raízes de tamanho miúdo, médio e graúdo. Resultados de dez ensaios da terceira série experimental.

Autores norte-americanos têm observado muitas vêzes efeitos semelhant es do espaçamento sôbre a produção bruta da batata doce. Brooks e out ros (6), trabalhando no Tennesse, com diversas variedades, obtiveram 
aumentos gradativos e substanciais na produção, quando os espaçamentos entre plantas foram reduzidos de 60 para 45 , e 31 para $15 \mathrm{~cm}$. Anderson, Cochran e outros (2), trabalhando, em Mississipi e Texas, com a variedade "Pôrto Rico", e com a forrageira "Triumph", mantendo fixa em $107 \mathrm{~cm}$, a distância entre linhas, verificaram que, variando de 20 a $60 \mathrm{~cm}$, os espaçamentos entre plantas, as produções brutas médias decresceram, embora com diferenças não significativas. Ainda em Mississipi, Anderson e Randolph (3) obtiveram, com os mesmos tratamentos, queda significativa na produção bruta com o aumento do espaçamento, entre plantas, de 30 para $40 \mathrm{~cm}$, de 60 para $107 \mathrm{~cm}$, bem como de 80 para $107 \mathrm{~cm}$. Não se verificaram, porém, diferenças significativas, entre os espaçamentos de 20 e $30 \mathrm{~cm}$. Adotando entre as linhas, o mesmo espaçamento de $107 \mathrm{~cm}$, Cochran (7), trabalhando na Geórgia, verificou que o espaçamento entre as plantas só afetou as produçбes brutas, quando as plantas foram espaçadas de mais de $60 \mathrm{~cm}$, provocando diminuição na produção.

Os resultados dos ensaios apresentados neste trabalho, mostraram que os espaçamentos tiveram efeitos bastante sensíveis sôbre as produções das diversas classes de batatas. Diminuindo-se o espaçamento, tanto entre plantas como entre linhas, obteve-se considerável aumento na produção das batatas miúdas e considerável diminuição na de batatas graúdas. (figs. 1 e 2). Isso significa que a diminuição dos espaçamentos resulta também na diminuição do tamanho médio das batatas, fato que é confirmado pelos dados obtidos sôbre os pesos médios das raízes (figuras 1 e 2).

Com relação às batatas de tamanho médio, a classe preferida nos mercados mais exigentes, verificou-se, nos ensaios da terceira série, que a diminuição dos espaçamentos, sobretudo entre linhas, beneficiou bastante a sua produção. Examinando-se a figura 3, pode-se notar que as produçóes de batatas da classe média aumentaram sensivelmente quando se diminuiram as distâncias entre plantas de 50 para $30 \mathrm{~cm}$ e de 30 para $20 \mathrm{~cm}$. Nos ensaios da primeira série não se observam efeitos consistentes dos espaçamentos sôbre a produção de batatas de tamanho médio. As maiores produçóes foram obtidas no espaçamento intermediário de $75 \times 40 \mathrm{~cm}$. Deve-se, no entanto, considerar que esta série constou apenas de dois ensaios e a classificação obedeceu critério diferente.

Resultados comparáveis aos obtidos nos ensaios da primeira série com relação à influência do espaçamento sôbre o tipo de batatas, têm sido obtidos por vários autores norte-americanos. Miller e Kimbrough (8), trabalhando na Louisiana, em solo bem fértil, com cinco diferentes espaçamentos entre as plantas e nas linhas variando entre 23 e $53 \mathrm{~cm}$, obtiveram maiores produções de raízes graúdas (jumbo), nos espaçamentos maiores. Com um dos menores espaçamentos experimentados, $30 \mathrm{~cm}$ entre plantas, obtiveram as mais altas produções tanto brutas como do tipo "mercado" (U.S. n. . ).

Anderson e outros (1), em diferentes localidades dos EE.UU., obtiveram pequena variação, devidas ao espaçamento, na produção do tipo "mercado", mas verificaram que, em geral, os espaçamentos mais juntos resultaram na produção de maiores quantidades de batatas dêste tipo. Estudando espaçamentos relativamente pequenos entre plantas, variando entre 
15 e $38 \mathrm{~cm}$ com espaçamento grande, fixo de $120 \mathrm{~cm}$, entre as linhas, Beattie e outros $(4,5)$ verificaram que a diminuição do espaçamento entre as plantas provocou diminuição na proporção de raízes de tamanho graúdo (jumbo), e que o emprêgo do espaçamento mínimo, de $15 \mathrm{~cm}$, fêz aumentar a proporção das raízes miúdas (U.S. $n .^{\circ}$ 2). Os espaçamentos experimentados não afetaram apreciàvelmente a produção do tipo "mercado" (U.S. n. ${ }^{\circ} 1$ ), bem como a produção total bruta.

A variação apenas da forma da superficie retângula dada a cada planta, mantendo inalterável a área correspondente, embora não tenha revelado efeitos significativos sôbre a produção das diferentes classes de batatas, mostrou nas experiências aqui apresentadas apreciável efeito sôbre as produçoes de raízes. Os dados da segunda série experimental (quadro 3) revelaram, em ambos os ensaios ( . $^{\circ} 3$ e 4 ), que as produções brutas médias aumentaram sensivelmente à medida que as distâncias entre plantas diminuiram e as entre linhas aumentaram. Em um dos ensaios, instalado em Campinas, o teste de " $F$ " mostrou-se altamente significativo para tratamentos.

Ao contrário do que se acreditava, não se verificou influência sensivel dos diferentes espaçamentos sôbre a conformação das batatas, apesar de terem mostrado grande influência sôbre o tamanho médio. Resultados semelhantes têm sido encontrados por outros autores $(2,3)$.

Baseando-se nos dados apresentados neste trabalho, para as condições do Estado de São Paulo, bem como nos resultados obtidos pelos autores norte-americanos, pode-se recomendar :

a) Entre plantas, devem ser adotadas distâncias pequenas, próximas de $20 \mathrm{~cm}$, quando se deseja obter batatas de tamanho médio ou pequenas, próprias para os mercados exigentes dos grandes centros consumidores, como o da capital de São Paulo. Esse espaçamento pode ser aumentado para 30 ou $40 \mathrm{~cm}$, quando não houver restriçzes quanto ao tamanho das batatas desejadas.

b) Entre linhas, como é relativamente pequena a influência das distâncias sôbre a produção de batatas de tamanho próprio para o mercado e nenhuma sôbre a produção bruta total, recomendam-se os espaçamentos que tragam maiores facilidades no preparo dos camalhões e menores despesas nas várias fases da cultura. Assim, nas culturas pequenas e intensivas dos arredores de São Paulo, onde o trabalho, pela irregularidade do terreno, é pouco mecanizado, sendo difícil levantar grandes camalhoes, devem ser adotados espaçamentos relativamente pequenos, de 70 a $80 \mathrm{~cm}$. Nas culturas mais extensivas do interior, os melhores espaçamentos entre camalhões estarão entre 80 e $100 \mathrm{~cm}$. Adotando-se distâncias maiores, próximas de $100 \mathrm{~cm}$, economizam-se ramas e trabalho no plantio, diminui-se o trabalho na colheita, pois se terá por área cultivada menor número de linhas para colhêr, e ainda se facilita o trabalho no cultivo, que poderá ser mais fàcilmente mecanizado.

\section{5 - RESUMO E CONCLUSÕES}

Para estudar o efeito do espaçamento, em seus vários aspectos, na cultura da batata doce, e determinar os mais indicados para os diferentes 
propósitos em que se faz a sua cultura em São Paulo, foi iniciado, em 1939/40, extenso plano experimental cuja execução se prolongou até 1948/49. Êsse plano, compreendendo dezessete experiências individuais, foi executado em cinco diferentes estações experimentais do Instituto Agronômico, dêle constando três séries distintas de ensaios, com diferentes tratamentos.

Foram experimentadas várias combinações de espaçamentos, com distûncias variáveis de 60 a $100 \mathrm{~cm}$ entre linhas e de 20 a $50 \mathrm{~cm}$ entre plantas, nas linhas. Em todos os ensaios, os delineamentos adotados foram em blo$\cos$ ao acaso, com 4 repetições.

Obtiveram-se dados sôbre o desenvolvimento de ramas, ocorrência de falhas e classificação do produto. Segundo o pêso das raízes, foram consideradas as classes : miúda (menor de $80 \mathrm{~g}$ ), média (de 80 a $800 \mathrm{~g}$ ) e graúda (mais de $800 \mathrm{~g}$ ), e calcularam-se os pesos das raízes.

Os resultados mostraram que a diminuição das distâncias entre plantas de 50 para $30 \mathrm{~cm}$ e de 30 para $20 \mathrm{~cm}$, com qualquer dos espaçamentos entre linhas, provocou sensíveis aumentos na produção bruta de raízes bem como na quantidade de raízes de tamanho médio, classe preferida pelos mercados. Essa redução do espaçamento revelou efeitos ainda mais sensíveis sôbre o tamanho das batatas produzidas. Com efeito, diminuindo-se a distância entre plantas, aumentaram-se as produções de batatas de tamanho miúdo, diminuiram-se as produções das de tamanho graúdo e, bem assim, diminuiu-se o pêso médio geral das batatas colhidas.

As distâncias entre linhas, ou camalhões, não tiveram efeito algum sôbre as produções brutas, mas revelaram certos efeitos no sentido de aumentar as produções das batatas miúdas e médias, e de diminuir as graúdas, quando se diminuiu o espaçamento de 100 para $75 \mathrm{~cm}$.

Em ensaios onde se estudaram diferentes espaçamentos entre linhas e plantas, mantendo sempre a mesma área por planta, verificou-se que as diferentes combinações não influiram, significativamente, nem sôbre as produções das diferentes classes de raízes nem sôbre o pêso médio. Obtiveram-se, entretanto, produções brutas mais elevadas, no tratamento em que se adotou a distância máxima entre linhas, de $100 \mathrm{~cm}$, e a distância mínima entre plantas, de $30 \mathrm{~cm}$.

Diante dos resultados obtidos, podem ser feitas as seguintes recomendações :

a) Para as culturas intensivas dos arredores da Capital paulista, visando a produção de batatas para mesa, ou em qualquer caso em que se deveja obter grande proporção de batatas pequenas, devem ser adotados espaçamentos de 70 a $80 \mathrm{~cm}$ entre linhas e de $20 \mathrm{~cm}$ entre plantas, nas linhas.

b) Para as culturas mais extensivas, visando o abastecimento do mercado do interior, menos exigente quanto ao tipo do produto, devem ser adotados espaçamentos de 90 a $100 \mathrm{~cm}$ entre linhas ou camalhões e 30 cm entre as plantas, nas linhas.

c) Quando se visa a produção de batatas para forragem ou para fins industriais, casos em que não há restrições quanto ao tipo das batatas, devem ser adotados espaçamentos de 90 a $100 \mathrm{~cm}$ entre linhas ou camalhões, e de $40 \mathrm{~cm}$ entre as plantas, nas linhas. 


\section{SUMMARY AND CONCLUSIONS}

The effect of spacing on the total yield and on the size of sweet potatoes was studied in seventeen experiments comprising three series of tests with several treatments, carried out at five experiment stations in the State of São Paulo, from 1939/40 to 1948/49.

Several combinations of spacing from 60 to $100 \mathrm{~cm}$ between rows and 20 to $50 \mathrm{~cm}$ between hills in the rows were tried out. Randomized blocks with four replications were used in all experiments.

Observation were made on development of the vines, occurrence of failures and types of roots produced. These roots were classified according to weight in three types as follows: small (less than 80 grams); medium (from 80 to 800 grams) and large (more than 800 grams). The average weight of roots (total yield divided by number of roots) was calculated for each treatment.

The results obtained in these experiments indicated that in the rows 60 to $100 \mathrm{~cm}$ apart, the reduction of spacing between plants in the rows from 50 to $30 \mathrm{~cm}$ and from 30 to $20 \mathrm{~cm}$ resulted in an increase in total root yield and also in the amount of roots of average size, that is the type which is more valuable for the large consuming market. The smaller spacing in the rows favored also the production of small and medium sized roots and reduced considerably the amount of large-sized sweet potatoes. The average root weight was also increased.

Total root yield was not affected by variations in the spacing between rows. However, when spacing between rows was reduced from 100 to $75 \mathrm{~cm}$, an increase was noted in the average root weight and also in the quantity of small and medium sized roots. The amount of large sized sweet potatoes was reduced.

When the same area per plant was maintained, the variable spacing used has not influenced the size and average weight of the roots but highest total root yield was obtained when plants were set $30 \mathrm{~cm}$ apart in rows spaced $100 \mathrm{~cm}$ apart.

Based on the results of these experiments the following recommendations can be made for planting sweet potatoes in the State of São Paulo:

a) When small sized sweet potatoes are desirable, the spacing of 70 to $80 \mathrm{~cm}$ between rows and $20 \mathrm{~cm}$ in the lines can be adopted. For intensive cultivation in small areas, as is usual near the city of São Paulo, where the market prefers the small sized type, this spacing can be recommended.

b) For more extensive plantings and when the small-sized type is not particularly required a larger spacing might be used, as at closer spacing an additional quantity of vines and more labor are necessary. The recommended spacing at this case is 90 to 100 $\mathrm{cm}$ between rows and $30 \mathrm{~cm}$ in the rows.

c) When the roots are to be used for feeding livestock or for industrial purposes where there is no restriction to size and weight of roots, wider spacing between plants may be used. The recommended is 90 to $100 \mathrm{~cm}$ between rows and $40 \mathrm{~cm}$ within the row.

\section{LITERATURA CITADA}

1. Anderson, W. S., E. A. Currey, E. B. Ferris e J. C. Robert. Sweetpotato plant spacing. Bull. Miss. agric. Exp. Sta. 358 : 1-19. 1941.

2. Anderson, W. S., H. L. Cochran, J. B. Edmond, O. B. Garrison, R. E. Wright e Victor R. Boswell. Regional studies of time of planting and hill spacing of sweetpotatoes. Circ. U.S. Dep. Agric. 725 : 1-20. 1945.

3. Anderson, W. S. e John W. Randolf. Sweetpotato production. Time of planting and hill spacing studies. Bull. Miss. agric. Exp. Sta. 378 : 1-22, 1943.

4. Beattie, J. H., Victor R. Boswell e E. E. Hall. Influence of spacing and time of planting on the yield and size of the Porto Rico sweetpotato. Circ. U.S. Dep. Agric. 327 : 1-10. 1934. 
5. Beattie, J. H., Victor R., Boswell e J. D. Mc Cown. Sweetpotato propagation and transplanting studies. Circ. U.S. Dep. Agric. 502 : 1-15. 1938.

6. Brooks D. Drain e outros. Sweetpotato culture. Varieties, spacing, date of setting and date of digging. Bull. Tenn. agric. Exp. Sta. 189: 1-24. 1944.

7. Cochran, H. L. Influence of time of planting and spacing on the yield of Porto Rico and Triumph sweetpotatoes. Bull. Ga. Exp. Sta. 230 : 1-26. 1943.

8. Miller, Julian C. e W. D. Kimbrough. Sweetpotato production in Louisiana. Bull. La. agric. Exp. Sta. 281 : 1-23. 1936.

9. Pais de Camargo, A. A Adubação da batata doce em São Paulo. Bragantia 11: 55-79, fig. 1. 1951. 